DOI: $10.17516 / 1997-1370-0764$

УДК 008

\title{
Language Temporality as Culture Metaphor
}

\author{
Oksana V. Rtischeva* \\ Kemerovo State University of Culture and Arts \\ Kemerovo, Russian Federation
}

Received 30.03.2021, received in revised form 20.04.2021, accepted 21.05.2021

\begin{abstract}
The article considers issues of defining language temporality through content for communication between language and thinking in the world conceptualization regarding the ideas of time developing in culture. The author notes the role of the person in modeling language temporality based on which the general worldview reflecting existential understanding of culture is constructed. Moreover, the author underlines that consideration of language temporality is defined by specifics of time perception as the objected universal forming a conceptual basis of culture. Metaphorical ways of exteriorization of language temporality in perception of typical repeatability of an event row are revealed (B.L. Whorf). The author considers metaphorization of culture in implementing language temporality through the identification of time and human life. In addition, the author notes that integration of models between time and life is not always subjected to logical coordination and definition. Time as a natural process represents the movement caused by natural laws, which set the formalized principles of the consecutive changes, which are abstractly presented in the straight line (infinity). However, assessment and understanding of the movement direction is possible if the straight line becomes discrete, as only in this case it is possible to speak about the components of the whole pointing out its sense, that is possible to present in the form of the points located on the straight line. This discretization defines differences in understanding of time that is dictated by metaphorical sense of language temporality and culture, since a lack of opportunities for unambiguous interpretation of changes generate modifications of meanings which lie in the nature of defining time and its goal-setting.
\end{abstract}

Keywords: language temporality, language metaphor, culture metaphor, cultural universal, space and time, time model, value in culture, a worldview.

Research area: culturology.

Citation: Rtishcheva, O.V. (2021). Language temporality as culture metaphor. J. Sib. Fed. Univ. Humanit. Soc. Sci., 14(6), 834-841. DOI: 10.17516/1997-1370-0764.

(c) Siberian Federal University. All rights reserved

* Corresponding author E-mail address: ortishheva@mail.ru ORCID: 0000-0003-2861-471X 


\title{
Языковая темпоральность как метафора культуры
}

\author{
O.В. Ртищева \\ Кемеровский государственный институт культуры \\ Российская Федераичия, Кемерово
}

\begin{abstract}
Аннотация. Рассматриваются вопросы определения языковой темпоральности сквозь призму содержания связи языка и мышления в концептуализации мира в отношении к представлениям о времени, складывающимся в культуре. Отмечается роль человека в моделировании языковой темпоральности, на основе которой строится всеобщая картина мира, отражающая бытийное понимание самой культуры. Рассмотрение языковой темпоральности определяется спецификой восприятия времени как объективизированной универсалии, образующей концептуальную основу культуры. Выявляются метафорические способы экстериоризации языковой темпоральности в восприятии типичной повторяемости событийного ряда (Б. Уорф). Метафоризация культуры в осуществлении языковой темпоральности рассматривается в аспекте идентификации времени и жизни человека. Отмечается, что интеграция моделей времени и жизни не всегда поддается логическому согласованию и определению. Время как естественный процесс представляет собой движение, обусловленное естественными законами, которые задают формализованные принципы последовательных изменений, абстрактно представляемых в видепрямой (бесконечности). Но оценка ипонимание направления движения возможны, если эта прямая становится дискретной, поскольку только в этом случае возможно говорить о составляющих целого, указывающих на его смысл, что можно представить в виде точек, располагающихся на линии. Эта дискретность определяет различия в понимании времени, что диктуется метафоричностью языковой темпоральности и самой культуры, поскольку отсутствие возможностей однозначного толкования изменений порождает модификации смыслов, которые заключаются в самом характере определения времени и его целеполагания.
\end{abstract}

Ключевые слова: языковая темпоральность, языковая метафора, метафора культуры, культурная универсалия, пространство и время, модель времени, ценность в культуре, картина мира.

Научная специальность: 24.00.00 - культурология.

\section{Введение}

Традиционно исследование языковой темпоральности определяется пониманием времени как языкового конструкта, проявляющегося в понятийных или грамматических категориях, закрепленных в соответствующих формах выражения. Однако языковая темпоральность не ограничивается характеристиками номинативных, грамматических или словообразовательных и лексических признаков, важно осознание связи языка и самого мышления в системе концептуализации мира в отношении к представлениям о времени, складывающемся в определенной культуре. Хотя на первый взгляд может возникнуть ощущение, что время - это самостоятельная категория, которая отражает одномерность и необратимость всеобщего линейного движения. Однако важную роль в моделировании этого процесса играет сам человек, устанавливающий смыслы очевидного прошлого, неизвестного будущего и переживаемого настоящего, что порождает ощущение всеобщего движения, идентифицируемого с жизнью человека и бытийным 
пониманием самой культуры. Указывая на ее сущностные характеристики в аспекте бытийного определения, языковая темпоральность задает исходные координаты, на основе которых строится всеобщая картина мира. «Понимание времени как культурной универсалии представляется основанием для выявления ценностных доминант в характеристике мировоззренческих устремлений человека, определяющихся его суждениями о закономерностях и случайностях, о смерти и бессмертии, о смысле жизни и своем предназначении и т. д.» (Astakhov, 2016: 34). Поэтому рассмотрение языковой темпоральности зачастую определяется спецификой восприятия времени как объективизированной универсалии, образующей концептуальную основу культуры.

\section{Концептологические \\ основания исследования}

Действительно, именно время отражает ритм жизни человека, ритм всех изменений культуры. В связи с этим Б. Уорф, характеризуя наши представления о времени, указывал на их объективизированный статус, что соответствует историчности всех процессов и особенностям их «регистрации». В своей работе «Отношение норм поведения и мышления к языку», отличающейся особым пониманием языка в контексте аристотелевской традиции связи философских и грамматических категорий, исследователь писал: «Наше же объективизированное время вызывает в представлении чтото вроде ленты или свитка, разделенного на равные отрезки, которые должны быть заполнены записями. Письменность, несомненно, способствовала нашей языковой трактовке времени, даже если эта языковая трактовка направляла использование письменности. Благодаря взаимообмену между языком и всей культурой мы получаем, например:

1. Записи, дневники, бухгалтерию, счетоводство, математику, стимулированную счетом.

2. Интерес к точной последовательности - датировку, календари, хронологию, часы, исчисление зарплаты по затраченному времени, измерение самого времени, время, как оно применяется в физике.

3. Летописи, хроники - историчность, интерес к прошлому, археологию, проникновение в прошлые эпохи, выраженные классицизмом и романтизмом» (Whorf, 2003: 191).

В этих примерах отчетливо прослеживается идея отражения в языке объективизированного времени, в наших представлениях эта связь прошлого и будущего выступает со всей очевидностью и выражается в соответствующих расчетах, хронологиях, хрониках и др. Так осуществляется экстериоризация языковой темпоральности в соответствующих процессах семантизации и формантизации. Подобное измерение времени способствует его соотношению с пространственными единицами. Это уже не «бесформенная субстанция», а материально выраженное образование, способствующее его категориальному представлению, что отчетливо выражается в европейских языках. В этих суждениях Б. Уорф развивает идеи В. фон Гумбольдта о связи языка и мышления, взаимообусловленность которых диктуется их рассмотрением сквозь призму самоосуществления человека в культуре (Rtischeva, 2018: 49-54). Однако в рассуждениях В. фон Гумбольдта о языковых практиках сквозь призму проявления мыслительной активности человека значимо понимание духовной человеческой силы как всеобъемлющей основы содержания культуры, которая обеспечивает ее целостность: «Впрочем, рассматривать ли язык как определенное миросозерцание или как способ сочетания мыслей - ибо он объединяет в себе и то и другое, - он всегда с необходимостью опирается на совокупность человеческой духовной силы; из нее нельзя ничего исключить, потому что она охватывает собою все» (Humboldt, 2000: 66).

Понятия «человеческая духовная сила», «народный дух» и др., связанные в представлениях В. фон Гумбольдта с влиянием немецкого романтизма, Б. Уорф рассматривает как идеализированные представления. Особое значение Б. Уорф 
придает пониманию времени в связи с проявлением типичных форм суждения человека: «Таким образом, наш лингвистический детерминированный мыслительный мир не только соотносится с нашими культурными идеалами и установками, но вовлекает даже наши собственно подсознательные действия в сферу своего влияния и придает им некоторые типические черты» (Whorf, 2003: 193). Поэтому представления человека о времени реализуются в восприятии типичной повторяемости событийного ряда, что в конечном итоге определяет и его поведение. Таким образом, человек отбирает и предпочитает все то, что соответствует устойчивому взгляду, либо адаптируется к существующей системе представлений. В связи с этим Б. Уорф пишет: «Влияние такого понимания времени на наше поведение проявляется еще и в том, что однообразие и регулярность, присущие нашему представлению о времени (как о ровно вымеренной безграничной ленте), заставляют нас вести себя так, как будто это однообразие присуще и событиям. Это еще более усиливает нашу косность. Мы склонны отбирать и предпочитать все то, что соответствует данному взгляду, мы как будто приспосабливаемся к этой установившейся точке зрения на существующий мир» (Whorf, 2003: 193).

Типичным проявлением такого влияния Б. Уорф считает жестикуляцию, которая сопровождает речевую активность, что свидетельствует об объективизированном восприятии времени, выражающемся в стремлении к его пространственному закреплению. Очень многие жесты служат для иллюстрации движения в пространстве, но отражают внепространственные представления, которые трактуются в языке с помощью метафор. С помощью жестикуляции реализуется попытка преодоления многозначности метафорического высказывания. Но, конечно, непространственное понятие при использовании жеста не станет более понятным, если отсутствует пространственная аналогия. Жестикуляция выступает свидетельством стремления человека к закреплению временного движе- ния в пространственном контексте, что выражается посредством метафоры, в которой согласуются эти полярные измерения.

Развивая эту мысль, Б. Уорф обращается к феномену кинестезии, физическому ощущению движения тела. Автор отмечает, что она возникла до языка и «должна сделаться значительно более осознанной через лингвистическое употребление воображаемого пространства и метафорическое значение движения» (Whorf, 2003: 194). Peзультатом развития кинестезии, ориентированной на физическую фиксацию времени, воплощаемой в динамике пространственных изменений, явилось развитие таких областей европейской культуры, как искусство и спорт, в основе которых лежит «поэзия движения».

Далее Б. Уорф акцентирует внимание на возможности закрепления пространственных изменений в синестезии: «Синестезия, или возможность восприятия с помощью органов какого-то одного чувства явлений, относящихся к области другого чувства, например восприятие цвета или света через звуки и наоборот, и потом должна была бы сделаться более осознанной благодаря лингвистической метафорической системе, которая передает непространственное представление с помощью пространственных терминов, хотя, вне всяких сомнений, она возникает из более глубокого источника» (Whorf, 2003: 195). Глубинный смысл синестезии связан с интеграцией пространственного и непространственного (временно́го) восприятий, так предметное видение синтезируется с чувственной и мыслительной активностью, в результате чего появляется метафора. Таким образом, автором утверждается то, что языковая темпоральность находится в зависимости от метафорического характера обозначения мира.

Эти идеи Б. Уорфа развивает Н. Д. Арутюнова, обращая внимание на то, что метафоризация времени, порождаемая бытийным толкование мира, выражающимся в его временно́й оценке, приводит к противоречию, о котором писал еще О. Шпенглер: «Если, с некоторой оговоркой, можно 
причинную форму духа назвать застывшей судьбой, то также возможно глубину пространства, эту основу формы мира, обозначить как застывшее время. [...] Как жизнь приводит к смерти, а сознание к созерцаемому, так равно и направленное время приводит к пространственной глубине. Здесь перед нами тайна, прафеномен, который нельзя разложить понятиями, а можно только принять таким, каков он есть; однако смысл его можно угадывать» (Spengler, 1993: 247). По логике автора пространство и время в соответствии с характером их реализации антагонистичны. Пространство реализуется вне времени, как и время неспособно быть закрепленным в пространстве. Поэтому, по мнению Н.Д. Арутюновой, метафоризация в осуществлении языковой темпоральности - это следствие бытийного конфликта. Исследователь отмечает, что «избежать противоречий можно лишь допустив множественность моделей времени, присутствующих в обыденном сознании людей и отраженных в «языке времени», построенном, как языки других отвлеченных понятий, на метафорах и аналогиях» (Arutuynova, 1997: 53).

Подобная неоднозначность реализации языковой темпоральности приводит Н.Д. Арутюнову к идее ее рассмотрения в двух отношениях:

- как языковой модели, которая ориентировано на само время, «Поток времени»;

- как языковой модели, в основе которой главной фигурой является человек, «Путь человека».

С одной стороны, это космическое время, определяемое природными циклами солнечными или лунными, естественными законами, действие которых лишь изредка потрясают взрывы и катастрофы, поэтому для него свойственна относительная нормированность. С другой стороны, это время субъектное, определяемое событийным рядом социальной и индивидуальной жизни, осуществляемой в свободном целеполагании, поэтому для него свойственна некоторая доля случайности. Это аспект понимания времени отмечался еще Д.С. Лихачевым: «Ощущение времени у человека, как известно, крайне субъективно. Оно может «тянуться» и может «бежать». Мгновение может «остановиться», а длительный период «промелькнуть»» (Likhachev, 1979: 211).

\section{Модели языковой темпоральности}

Модели языковой темпоральности находятся в сложных связях и отношениях, порождающих метафоры, указывающие на идентификацию времени и жизни человека. В связи с этим Н.Д. Арутюнова пишет: «Сближение моделей времени и моделей жизни естественно. Жизнь протекает во времени и подчинена его законам. Как и время, жизнь человека необратима и одномерна (линейна): каждый наступающий момент времени снимает альтернативы. Даже кривой путь прям. Жизнь измеряется в единицах времени. Она имеет начало и конец. Воплощенность времени в земном существовании заставляет различать конечное время и вечность. Конечное время наблюдаемо в изменениях. Вечность их останавливает» (Arutuynova, 1997: 53). Однако интеграция моделей времени и жизни не всегда поддается логическому согласованию и определению. Время как естественный процесс представляет собой движение, обусловленное естественными законами, которые задают формализованные принципы последовательных изменений, абстрактно представляемых в виде прямой или бесконечности. Но оценка и понимание направления движения возможны, если это прямая становится дискретной, поскольку только в этом случае возможно говорить о составляющих целого, указывающих на его смысл, что можно представить в виде точек, располагающихся на линии. В этой ситуации появляется осознание прошлого, будущего, настоящего и, соответственно, направления движения, что способствует установлению каузальных связей событий, составляющих общее движение. Однако эта дискретность не задается как должная характеристика движения, она становится возможной благодаря человеку. Как справедливо отмечает Н.Д. Арутюнова: «Ведь 
именно человек находится в точке присутствия, которая условно членит линию времени ка составляющие. Войдя в модель времени, человек внес в нее два сложных и противоречивых компонента: точку и движение, а вместе с движением и направление движения. Точкой присутствия стала и точкой зрения» (Arutuynova, 1997: $52-53)$.

Продолжая логику рассуждения автора, можно констатировать то, что точка присутствия человека становится фактором самоосуществления культуры, характеристики которой выражаются в языковой темпоральности. В связи с этим Л.Н. Михеева пишет: «Значит, наряду с внешней по отношению к языку моделью времени существует и внутриязыковая модель, конститутивным компонентом которой является точка присутствия в ней говорящего, от которого идет отсчет времени вправо - в будущее и влево - в прошедшее. Такую модель правильнее было бы называть уже не языковой, а речевой, где в качестве точки отсчета времени выступает субъект в момент высказывания» (Mikheeva, 2006: 149-150). В этих суждениях внимание акцентируется на том, что в качестве ключевого аспекта языкового представления времени становится осознание активности самого субъекта. Его включенность во временной континуум определяет характер понимания движения мира, что закрепляется в системе ценностей определенной культуры.

В различных исследованиях поразному определяются модели времени в соответствии с характером установления ценностных ориентиров в культуре и их языковой репрезентации. Некоторые тезисные обобщения существующих исследовательских практик представлены в работе Е.А. Николаевой, в которой выделяются следующие модели времени:

- хронологическое время проявляется как объективное время событий; релятивное время проявляется в понятиях «раньше - одновременно - позже»; эгоцентрическое время связано с моментом осознания времени как настоящего, прошедшего и будущего (В. Я. Мыркин);
- физическое время является исходным, фиксирует события при помощи даты и превращает их в факты; метафизическое время сопоставляется с однопорядковыми сущностями (материей, пространством, движением), осмысляется (рационализируется, опредмечивается) и вписывается в объективную картину мира, объединяя ее фрагменты и придавая ей целостность и законченность; бытовое время предстает как невосполнимый ресурс, подчиненный субъекту, духовное время, характеристиками которого служат трансцендентальность, феноменологичность, космопланетарность, сакральность, абсолютность (Н.К. Рябцева);

- рациональное / аналитическое время характеризуется рациональностью и внеположенностью (т. е. взглядом со стороны, невключенностью субъекта в объекет описания) - это время стечения обстоятельств и сплетения событий самой разной природы и масштаба; исключительное / надбытовое время интерпретирует «внесрочные», уникальные, особо значимые события, отражает причастность субъекта речи к предмету описания, что обуславливает его особую эмоциональность; бытовое / повседневное время описывает повседневность, которая принадлежит человеку, измеряется, планируется, переживается (Е.С. Яковлева) (Nikolaeva, 2007: 74).

По мнению К.Г. Красухина в качестве базовых для человеческого мышления моделей времени выступают внешнее время (время как пространство), внутреннее время (время как жизненная сила), субъективное время (время как желание, мысль и т. д.) (Krasukhin, 1997: 63). В свою очередь Тань Аошуан выделяет линейно-историческое и традиционное, антропологическое время (Tan, 1997: 98).

Акцентируя внимание на различных способах реализации языковой темпоральности, этот ряд подходов к определению модификаций времени можно продолжить, однако ключевым фактором их конструирования остается характер субъектной активности, выступающей основанием ценностного содержания культуры. В этом случае 
необходимо осознавать внутренние механизмы реализации языковой темпоральности, в основе которой лежит противоречие, связанное с возможностью закрепления времени в пространстве, что порождает метафоричность суждений, отражающих сущностные характеристики самой культуры.

\section{Заключение}

Как справедливо отмечал А.Я.Гуревич: «Мало найдется других показателей культуры, которые в такой же степени характеризовали бы ее сущность, как понимание времени. В нем воплощается, с ним связано мироощущение эпохи, поведение людей, их сознание, ритм жизни, отношение к вещам. Достаточно указать на циклическое восприятие времени, доминировавшее у народов древнего Востока и в античности, и на финалистскую концепцию движения мира от сотворения его к концу, к слиянию времени с вечностью в средние века, для того чтобы стало ясным коренное различие в жизненной ориентации культуры древности и культуры средневекового христианства» (Gurevitch, 1984: 103). Ход историко-культурных изменений наглядно демонстрирует различия в понимании времени, определяющие характер ценностных ориентаций людей. И эти изменения диктуются метафоричностью языковой темпоральности и самой культуры, поскольку отсутствие возможностей однозначного толкования изменений порождают модификации смыслов, что заключается в самом характере определения времени и его целеполагания. Субъектная активность, отличающаяся от пассивных установок, реализующихся по метонимической оси мышления, проявляется в стремлении закрепить полярные представления о времени в пространственном измерении, что порождает метафорические высказывания, в которых закрепляются сущностные характеристики самой культуры. Таким образом, связь бытийной концептуализации и метафоризации осуществляемых в языке и культуре очевидна, и языковая темпоральность выступает свидетельством этих неоднозначных отношений и процессов.

\section{Список литературы}

Арутюнова, Н.Д. (1997). Время: модели и метафоры // Логический анализ языка. Язык и время, 51-61.

Астахов, О.Ю. (2016). Время как феномен культуры в творческой рефлексии русского символизма конца XIX - начала XX веков // Ученые записки Комсомольского-на-Амуре государственного технического университета, 3 (2), 34-39.

Гумбольдт, В. фон (2000). Избранные труды по языкознанию. Москва: Прогресс, 400 с.

Гуревич, А.Я. (1984). Категории средневековой культуры. Москва: Искусство, 350 с.

Красухин, К.Г. (1997). Три модели индоевропейского времени на материале лексики и грамматики // Логический анализ языка: язык и время, 62-77.

Лихачев, Д.С. (1979). Поэтика древнерусской литературы. Москва: Наука, 360 с.

Михеева, Л.Н. (2006). Языковое время как лингвокультурологическая универсалия: междисциплинарный подход к изучению // Вестник гуманитарного факультета ИГХТУ, 1, 145-151.

Николаева, Е.А. (2007). Время в языковой картине мира // Вестник ОГУ, 9, 72-75.

Ртищева, О.В. (2018). Культурный антропоцентризм языковых практик в лингвофилософии Вильгельма фон Гумбольдта // Ученые записки Комсомольского-на-Амуре государственного технического университета, 2, 2, 49-54.

Тань Аошуан (1997). О модели времени в китайской языковой картине мира // Логический анализ языка: язык и время, 96-106.

Уорф, Б. (2003). Отношение норм поведения и мышления к языку // Языки как образ мира, $157-201$

Шпенглер, О. (1993). Закат Европьы. Москва: Мысль, 1, 620 с.

$$
-840-
$$




\section{References}

Arutuynova, N.D. (1997). Vremya: Modeli i metafhory [Time: The models and metaphors]. In Logicheski analiz yazyka: Yazyk I vremya [Logical language analysis: Language and time], 51-61.

Astakhov, O. Yu. (2016). Vremya kak fenomen kul'tury v tvorcheskoi refleksii russkogo simvolozma kontsa XIX - nachala XX vekov [Time is as phenomena of culture in creative reflection of Russian symbolism of the end of the XIX beginning XX centuries]. In Uchenye zapiski Komsomol'sk-na-Amure gosudarstvennogo technicheskogo universiteta [Bulletin of Komsomol'sk-na-Amure State Technical University], 3 (2), 34-39.

Gurevitch, A. Ya. (1984). Kategorii srednevekovoi kul'tury [Categories of medieval culture]. Moscow, Isskustvo, $350 \mathrm{p}$.

Humboldt, W. v. (2000). Izbrannye trudy po yazykoznaniyu [The chosen works on linguistics]. Moscow, Progress, 400 p.

Krasukhin, K.G. (1997). Tri modeli indoevropeiskogo vremeni na materiale leksiki i grammatiki [Three models of Indo-European time on material of lexicon of grammar]. In Logicheski analiz yazyka: Yazyk I vremya [Logical analysis of language: Language and time], 62-77.

Likhachev, D.S. (1979). Poetika drevnerusskoi literatury [Poetics of Old Russian literature]. Moscow, Nauka, 360 p.

Mikheeva, L.N. (2006). Yazykovoe vremya kak lingvokul'turnaya universalia: mezhdistsiplinarnyi podhod [Language time as linguistic and cultural universal: cross-disciplinary approach to studying]. In Vestnik gumanitarnogo fakul'teta Ivanovskogo gosudarstvennogo khimiko-tekhnologicheskogo universiteta [Bulletin of Ivanov State Chemical and Technological University], 1, 145-151.

Nikolaeva, E.A. (2007). Vremya v yazykovoi kartine mira [Time in language picture of the world]. In Vestnik Orenburgskogo gosudarstvennogo universiteta [Bulletin of Orenburg State University], 9, 72-75.

Rtischeva, O.V. (2018). Kul'turnyi antropotsentrizm yazykovykh praktik v lingvofilosofii W. von Humboldt [Cultural anthropocentrism of linguistic practices in linguistic philosophy of W. von Humboldt]. In Uchenye zapiski Komsomol'skogo-na-Amure gosudarstvennogo tekhnicheskogo universiteta [Bulletin of Komsomol'sk-na-Amure State Technical University], 2, 2, 49-54.

Spengler, O. (1993). Zakat Evropy [Decline of Europe]. Moscow, Mysl', 1, 620 p.

Tan, Aoshuan. (1997). O modeli vremeni I kitaiskoi yazykovoi kartine mira [About the time model and Chinese language of the world]. In Logicheski analiz yazyka: Yazyk I vremya [Logical language analysis: Language and time], 96-106.

Whorf, B. (2003). Otnoshenie norm povedeniya i myshleniya k yazyku [The relation of habitual thought and behavior to language]. In Yazyki kak obraz mira [Languages as an image of the world], 157-201. 